\title{
Continuous-flow synthesis of doped all-inorganic perovskite nanocrystals enabled by a microfluidic reactor for light-emitting diode application
}

\author{
Pengcheng Lin ${ }^{1}$, Hongbin Chen ${ }^{1}$, Zhan Wei ${ }^{1}$, Yingru Lin ${ }^{1}$, Jinghui Lin ${ }^{1}$, Ying Chen ${ }^{1 *}$ and \\ Zhengdong Cheng ${ }^{2 *}$
}

\begin{abstract}
All-inorganic perovskite nanocrystals (AIPNCs) possess the advantages of narrow emission spectrum, high quantum efficiency of luminescence and tunable luminescence position, which show a broad application prospect in the fields of optoelectronic materials and devices. Ion doping can tune their pristine crystal structures and luminescent properties or endow the AIPNCs with additional functionalities. Herein, a microfluidic reactor is designed to produce the $\mathrm{Ce}^{3+}$-doped AIPNCs based on the continuous-flow reaction. The mechanism of the flow synthesis of $\mathrm{Ce}^{3+}$-doped AIPNCs is the efficient physical mixing of the precursor ions in the confined micro-channel, the reaction nucleation of crystal seeds in the poor solvent and the crystal growth of the doped AIPNCs along the flow direction. The synthesis process can be on-line monitored by an optical fiber absorption spectrometer and an optical fiber fluorescence spectrometer. The doping concentration of $\mathrm{Ce}^{3+}$ can be facilely controlled by changing the flow parameters in the microfluidic reactor, and the highest value reaches $1 \%$. The $\mathrm{Ce}^{3+}$ doping can improve the photoluminescence efficiency and the stability of the AIPNCs. The $\mathrm{Ce}^{3+}$-doped $\mathrm{CsPbBr}_{3}$ AIPNCs can be used to manufacture green light-emitting diodes (LEDs) with a high color purity of 93.3\% and white LEDs with correlated color temperature (CCT) of 10,436 K, CIE color coordinates of $(0.261,0.317)$ and color-rendering index (CRI) of 72.1. The continuous and controllable synthesis of AIPNCs by microfluidic reactor opens up new avenues for the application of the high-performance optoelectronic materials and devices.
\end{abstract}

Keywords: all-inorganic perovskite nanocrystals, microfluidics, ion doping, light-emitting diode

\section{INTRODUCTION}

In recent years, lead halide perovskites with excellent optoelectronic properties have become a kind of emerging luminescent materials [1-4]. Among them, all-inorganic perovskite nanocrystals (AIPNCs) $\mathrm{CsPbX}_{3}(\mathrm{X}=\mathrm{Cl}$, $\mathrm{Br}, \mathrm{I})$ possessing ultra-high photoluminescence quantum efficiency, narrow line width and wide color domain are expected to become a new generation of functional optical materials. Recent progress of AIPNC massive synthesis has promoted their advanced light-emitting diode (LED) applications [5,6]. AIPNC scintillators can be used to manufacture the flexible and highly sensitive $\mathrm{X}$-ray detector with a detection limit of $13 \mathrm{nGy} \mathrm{s}^{-1}$, which is $1 / 400$ of the radiation dose of general medical imaging [7]. AIPNCs have been demonstrated as a new class of superior optical-gain materials towards low-threshold and ultra-stable lasing $[8,9]$. AIPNCs have been used to fabricate high-performance and low-cost image sensors and chemical sensors [10,11]. AIPNC-based photodetectors and temperature sensors have shown high sensitivity and considerable feasibility, respectively $[12,13]$. AIPNCs are novel photocatalysts to convert $\mathrm{CO}_{2}$ into solar fuels, or to initiate the polymerization reaction $[14,15]$. AIPNCs can be combined with persistent phosphors to fabricate anti-counterfeiting materials [16].

Very recently, ion doping has been proposed as a chemical strategy to create the AIPNC homologues. The methodology for fabricating doped AIPNCs is partially or completely replacing the $\mathrm{Pb}^{2+}$ with main-group metal ions $\left(\mathrm{Ag}^{+}, \mathrm{Bi}^{3+}, \mathrm{Al}^{3+}, \mathrm{In}^{3+}, \mathrm{Ba}^{2+}, \mathrm{Sr}^{2+}, \mathrm{Ca}^{2+}, \mathrm{Li}^{+}, \mathrm{K}^{+}\right)$, transition

${ }^{1}$ Guangdong Provincial Key Laboratory of Functional Soft Condensed Matter, School of Materials and Energy, Guangdong University of Technology, Guangzhou Higher Education Mega Center, Guangzhou 510006, China

2 Artie McFerrin Department of Chemical Engineering, Texas A\&M University, College Station, Texas 77843-3122, USA

* Corresponding authors (emails: chenying@gdut.edu.cn (Chen Y); zcheng@tamu.edu (Cheng Z)) 
metal ions $\left(\mathrm{Zn}^{2+}, \mathrm{Cu}^{2+}, \mathrm{Ni}^{2+}, \mathrm{Mn}^{2+}\right)$ or rare-earth metal ions $\left(\mathrm{Ce}^{3+}, \mathrm{Tb}^{3+}, \mathrm{Eu}^{3+}, \mathrm{Yb}^{3+}\right)$. The heteroion doping of AIPNCs can realize the crystal growth control, structural stability control, light conversion control or optoelectronic performance control [17-20]. For instance, the $\mathrm{Mn}^{2+}$-doped AIPNCs present both high-energy band gap emission and low-energy down-converted emission of $\mathrm{Mn}^{2+}$ [21]. The $\mathrm{Ba}^{2+}$ doping can adjust the lattice microstructure, band structure, surface potential, electron affinity, dielectric properties and other electrical properties of AIPNCs towards high-performance nano-generators [22]. $\mathrm{Ni}^{2+}$ doping of AIPNCs can significantly tune their optical properties, introduce magnetic functionality and improve their chemical and photochemical stabilities [23]. The $\mathrm{Bi}^{3+}$-doped AIPNCs demonstrate broadened light absorption within the whole visible light region and excellent photostriction performances [24]. Doping $\mathrm{Al}^{3+}$ into the AIPNCs can extend the band gap and improve the stability of blue photoluminescence [25]. $\mathrm{Li}^{+}$doping can cause a lattice expansion and improve the electron injection efficiency in the AIPNC LED devices [26].

Previously, the main reaction routes to synthesize doped AIPNCs are hot-injection at high temperature and postsynthetic ion exchange. For instance, $\mathrm{Bi}^{3+}$-doped AIPNCs were synthesized by using a classic hot-injection method, and the incorporation concentration of $\mathrm{Bi}^{3+}$ into AIPNCs is $0.074 \%$ [27]. A halide exchange-driven cation exchange strategy was exploited to synthesize $\mathrm{Mn}^{2+}$ doped $\mathrm{CsPb}(\mathrm{Cl} / \mathrm{Br})_{3}$ nanocrystals via post-replacement of $\mathrm{Pb}^{2+}$ in the pre-synthesized AIPNCs [28]. Although the above-mentioned methods have been proved effective in synthesizing doped AIPNCs, the high reaction temperature, tedious reaction time, additional vacuum equipment, complex procedure, and discontinuous operation still remain to be optimized. In recent years, the microfluidic technique has been proposed as a versatile and robust method for the flow reactions and physical operations in liquid phases [29-31]. The key outcomes when using a microfluidic reactor instead of a batch reactor are the highly integrated reaction platform combining the reactant input, mechanical mixing, chemical nucleation, the online product monitoring and the dynamic control of product structures and properties. They are now widely used in nanomaterial synthesis, functional material assembly, drug release, biological analysis and so on [32-35]. Previously, the synthesis of doped AIPNC is generally conducted in the liquid phase with intense mechanical mixing. Therefore, the doped AIPNC synthesis by using microfluidic technique is practicable.
In this work, a multichannel co-flowing microfluidic reactor is put forward to synthesize the doped AIPNCs. The $\mathrm{Ce}^{3+}$-doped AIPNC is selected as a typical example. The liquid sealed space in the microfluidic chip generates a self-contained closed environment to block the air and moisture. The high-speed mixing of the reactant fluids in the micro-reactor ensures the efficient collision and combination of reactive particles. The nucleation and crystallization of the doped AIPNCs are conducted based on the phase separation of the precursor ions in a poor solvent at room temperature. The synthesis process can be on-line monitored by an optical fiber absorption spectrometer and an optical fiber fluorescence spectrometer. The doping concentration of $\mathrm{Ce}^{3+}$ can be continuously tuned by changing the flow rates of $\mathrm{Ce}^{3+}$ source. Overall, the microfluidic reactor to synthesize the doped AIPNCs proposed in this work demonstrates significant advantages over the traditional hot-injection setup, including reduced reaction temperature, reduced reaction time, unnecessary external vacuum equipment, continuous synthesis, dynamic control of the reaction condition and real-time monitoring.

\section{EXPERIMENTAL SECTION}

\section{Materials}

Lead bromide $\left(\mathrm{PbBr}_{2}, 99.5 \%\right.$, Aladdin), cesium bromide (CsBr, 99.9\%, Alfa Aesar), cerium bromide $\left(\mathrm{CeBr}_{3}, 99.5 \%\right.$, Aladdin), oleic acid (OA, 90\%, Aladdin), oleamine (OAM, 90\%, Alfa Aesar), N,N-dimethylformamide (DMF, analytical grade, Aladdin) and toluene (analytical grade, Aladdin) were directly used without further purifications. The blue phosphor $\left(\mathrm{BaMgAl}_{10} \mathrm{O}_{17}: \mathrm{Eu}^{2+}, 99 \%\right)$ and red phosphor $\left(\mathrm{K}_{2} \mathrm{SiF}_{6}: \mathrm{Mn}^{4+}, 99 \%\right)$ were purchased from Guangzhou Huakui Chemical Technology Co., Ltd. (China). The ultrapure water $(18.2 \mathrm{M} \Omega \mathrm{cm})$ was provided by a pure water machine (Angel, China). The capillary tubes and glass slides to make the microfluidic reactor were purchased form the Sailing Company.

\section{The fabrication of microfluidic reactor}

The co-flowing microfluidic reactor for the synthesis of $\mathrm{Ce}^{3+}$-doped AIPNCs was fabricated by coaxially assembling four cylindrical capillaries (two left capillaries, one middle capillary and one right capillary) on a glass slide as shown in Fig. 1a. First, the middle capillary with an inner diameter of $500 \mu \mathrm{m}$ and a length of $8 \mathrm{~cm}$ was tapered and sanded to have a 300- $\mu \mathrm{m}$ orifice. Then, two left capillaries with an inner diameter of $100 \mu \mathrm{m}$ and a length of $8 \mathrm{~cm}$ were inserted into the tapered middle capillary 


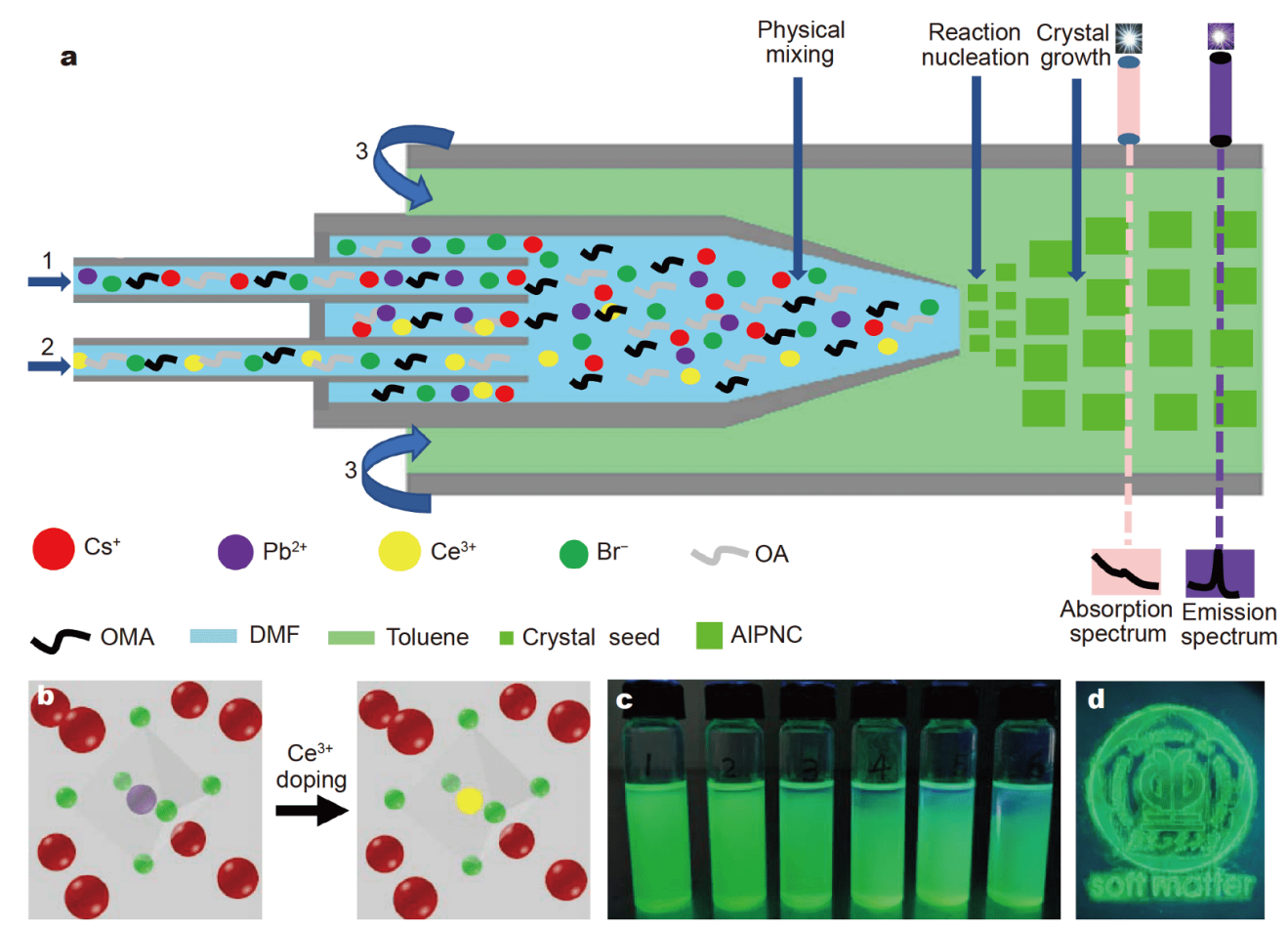

Figure 1 Continuous-flow synthesis of $\mathrm{Ce}^{3+}$-doped AIPNCs enabled by a microfluidic reactor. (a) The schematic of experimental setup for the continuous synthesis of $\mathrm{Ce}^{3+}$-doped AIPNCs based on the microfluidic reactor coupled with an optical fiber absorption spectrometer and an optical fiber fluorescence spectrometer. (b) The crystal structural model of the undoped $\mathrm{CsPbBr}_{3}$ AIPNCs and $\mathrm{Ce}^{3+}$-doped CsPbBr $\mathrm{AIPNCs}_{3}$ (c) Digital images of the undoped and doped AIPNCs when irradiated by UV light $(365 \mathrm{~nm})$, the flow rate ratios to prepare the samples from left to right are $0 \%$, $10 \%, 20 \%, 30 \%, 40 \%$ and $50 \%$. (d) The emblem of soft matter center of Guangdong University of Technology manufactured by screen printing of the $\mathrm{Ce}^{3+}$-doped AIPNC ink on a black substrate.

side by side on a glass slide, and the depth of insertion is $4 \mathrm{~cm}$. Lastly, both the left and middle capillaries were inserted into the right capillary with an inner diameter of $900 \mu \mathrm{m}$ and a length of $15 \mathrm{~cm}$, and the insertion depth of the middle capillary is $6 \mathrm{~cm}$. The interstice between the left capillaries and the middle capillary was sealed by epoxy resin, while the interstice between the middle capillary and the right capillary remained open.

\section{Synthesis of $\mathrm{Ce}^{3+}$-doped AIPNCs in the microfluidic reactor}

For the microfluidic synthesis of $\mathrm{Ce}^{3+}$-doped AIPNCs, the micro-reaction system was based on the physical mixing and chemical reaction of fluids 1,2 and 3 containing $\mathrm{Cs}^{+}$, $\mathrm{Ce}^{3+}, \mathrm{Pb}^{2+}$ and $\mathrm{Br}^{-}$as shown in Fig. 1a. Fluid 1 was prepared by dispersing $\mathrm{PbBr}_{2} \quad(0.4 \mathrm{mmol})$ and $\mathrm{CsBr}$ $(0.4 \mathrm{mmol})$ in the mixture composed of DMF $(10 \mathrm{~mL})$, OA $(1 \mathrm{~mL})$ and OAM $(0.5 \mathrm{~mL})$ with the assistance of ultrasound. Fluid 2 was prepared by dispersing $\mathrm{CeBr}_{3}$ $(0.4 \mathrm{mmol})$ in the mixture composed of DMF $(10 \mathrm{~mL})$, OA $(1 \mathrm{~mL})$ and OAM $(0.5 \mathrm{~mL})$ with the assistance of ultrasound. Fluid 3 was toluene. Fluid 1 and fluid 2 were independently injected into the two left capillaries, respectively. Fluid 3 was injected into the interstices between the right capillary and the middle capillary. The flow rate of fluid 1 was $20 \mu \mathrm{L} \mathrm{min}^{-1}$. The flow rate of fluid 2 was set to be $0,2,4,6,8$ and $10 \mu \mathrm{L} \mathrm{min}^{-1}$, and the flow rate ratios between fluid 2 and fluid 1 are $0 \%, 10 \%, 20 \%$, $30 \%, 40 \%, 50 \%$. The flow rate of fluid 3 was $100 \mu \mathrm{L} \mathrm{min}{ }^{-1}$. The flow rates of these fluids were independently controlled by syringe pumps (Harvard Apparatus).

\section{Fabrication of AIPNC-based green and white LEDs}

The AIPNCs were firstly mixed with silicone to form uniform AIPNC dispersions with the assistance of the ultrasound, the concentrations of the undoped and doped AIPNCs in the dispersions were $1 \mathrm{wt} \%$. Then, the AIPNC dispersions were placed on the surface of an ultraviolet (UV) LED chip of $370 \mathrm{~nm}$ and sealed by the epoxy resin under vacuum condition to obtain the AIPNC-based green LEDs. The blue phosphor $\left(\mathrm{BaMgAl}_{10} \mathrm{O}_{17}: \mathrm{Eu}^{2+}\right)$, green phosphor $\left(\mathrm{Ce}^{3+}\right.$-doped AIPNCs) and red phosphor $\left(\mathrm{K}_{2} \mathrm{SiF}_{6}: \mathrm{Mn}^{4+}\right)$ were dispersed in silicone and then deposited on the UV-LED chip of $370 \mathrm{~nm}$ from top to down 
to assemble a three dimensional (3D)-layered white LED chip. The concentrations of the blue, green and red phosphors in the silicone were $1 \mathrm{wt} \%, 1 \mathrm{wt} \%$ and $2 \mathrm{wt} \%$, respectively. The photoelectric properties of the AIPNCbased green and white LEDs were tested by an integrating sphere spectroradiometer system (LHS-1000, Everfine).

\section{Instruments and characterizations}

The powder X-ray diffraction (XRD) patterns of the undoped and doped AIPNCs synthesized in the microfluidic reactors were recorded by a powder X-ray diffractometer (Empyrean, PANalytical). The transmission electron microscopy (TEM) image and the high-resolution TEM images of the undoped and doped AIPNCs were obtained by a JEOL JEM 2100 transmission electron microscope. The high-angle annular dark-field scanning TEM (HAADF-STEM) images coupled with the energy dispersive spectrometer (EDS) element mapping for the $\mathrm{Ce}^{3+}$-doped AIPNCs were obtained by utilizing a Talos F200X STEM microscope $(200 \mathrm{kV})$, FEI. The ultravioletvisible (UV-Vis) absorption spectra were recorded by using a UV-Vis optical fiber absorption spectrometer (ocean optics USB2000+, USA). The photoluminescence (PL) emission spectra were recorded by an optical fiber fluorescence spectrometer (ocean optics STS, USA). The efficient $\mathrm{Ce}^{3+}$ doping concentration in the AIPNCs was determined by using a PerkinElmer Optima inductively coupled plasma-optical emission spectrometer (ICPOES). The absolute quantum yield measurements of the undoped and doped AIPNCs were conducted by a Varian FLR025 spectrometer. The PL images were recorded by a fluorescence microscope equipped with a $365 \mathrm{~nm}$ UV LED (Mingmei QS1, China). The temperature in the experiment was controlled by a temperature controller (INSTECH, HCS402-STC 200).

\section{RESULTS AND DISCUSSION}

In this work, a continuous-flow synthesis of doped AIPNCs in liquid phase is proposed by designing and constructing a microfluidic reactor. The complete experimental setup is composed of a multichannel coflowing microfluidic chip, an on-line optical fiber UV-Vis absorption spectrometer and an optical fiber PL spectrometer as illustrated in Fig. 1a. The detailed size parameters of the micro-reactor are listed in the experimental section. The microfluidic reactor provides a confined and sealed space for the physical mixing, reaction nucleation and crystal growth in the multifluids. The on-line spectrometers are introduced to monitor the real-time reaction state by recording the UV-Vis absorption spectra and the PL emission spectra of the flowing AIPNC colloids at the end of the microfluidic reactor. The liquidsealed space in the microfluidic reactor generates a selfcontained closed environment to block the air and moisture, which avoids the utilization of additional vacuum equipment required in the traditional hot-injection synthesis. Fluid 1 is the main fluid containing the dissociated $\mathrm{Cs}^{+}, \mathrm{Pb}^{2+}, \mathrm{Br}^{-}, \mathrm{OA}, \mathrm{OAM}$ and DMF. Fluid 2 is the doping fluid containing the dissociated $\mathrm{Ce}^{3+}, \mathrm{Br}^{-}, \mathrm{OA}$, OAM and DMF. Fluid 3 is the poor solvent toluene. The dissociated $\mathrm{Cs}^{+}, \mathrm{Pb}^{2+}, \mathrm{Br}^{-}$and $\mathrm{Ce}^{3+}$ in the main fluid and the doping fluid are stabilized by OA and OAM, thus ensuring the homogeneity of the injected reactants. It is noteworthy that the elongated tip of the middle capillary in the co-flowing microfluidic reactor provides more contact and collision for the physical mixing of the reaction precursor ions $\left(\mathrm{Cs}^{+}, \mathrm{Pb}^{2+}, \mathrm{Br}^{-}\right.$and $\left.\mathrm{Ce}^{3+}\right)$ in fluid 1 and fluid 2 due to the increased linear velocity along the cone area. Then, the mixed reaction precursors flow into fluid 3 containing the poor solvent toluene. The highspeed mixing of the precursor ions with fluid 3 ensures the efficient collision and combination of reactant particles to trigger the nucleation process and to generate the crystal seeds. Afterwards, the crystal seeds grow into the mature AIPNCs in the micro-reactor. Furthermore, the flowing DMF/toluene solvent can transfer the newborn AIPNCs from the reaction area to the external collection bottle, demonstrating a mini physical mixing-reaction nucleation-crystal growth route along the flow direction as shown in Fig. 1a. The nucleation and crystallization of the $\mathrm{Ce}^{3+}$-doped AIPNCs proceed based on the phase separation in a poor solvent as shown in Reaction (1) ( $x$ is the doping concentration). The corresponding structural models of the undoped and $\mathrm{Ce}^{3+}$-doped $\mathrm{CsPbBr}_{3}$ AIPNCs are illustrated in Fig. 1b, indicating the substitution of $\mathrm{Pb}^{2+}$ by $\mathrm{Ce}^{3+}$ in the lattice. The flow rate of the poor solvent $\left(Q_{3}=100 \mu \mathrm{L} \mathrm{min}{ }^{-1}\right)$ is controlled, far larger than those of the main fluid and the doping fluid, to provide a nonpolar liquid environment and to strengthen the mixing of the reactive fluids. The doping concentration of $\mathrm{Ce}^{3+}$ can be easily tuned by changing the flow rate ratios $\left(Q_{2} / Q_{1}\right)$ between the main fluid and the doping fluid. The $Q_{2} / Q_{1}$ ratios are $0 \%, 10 \%, 20 \%, 30 \%, 40 \%$ and $50 \%$ in this work. The resulting undoped/doped AIPNCs are collected by centrifugation, washed by toluene, and redispersed in toluene as shown in Fig. 1c. Both the undoped and doped AIPNCs can emit intensive green fluorescence when irradiated by UV light. The dispersion stability of the AIPNCs is basically decreased with the increase of $Q_{2} /$ $Q_{1}$ as the fluorescence location in the bottles gradually 
moves down. The accelerated aggregation of the doped AIPNCs in toluene is probably caused by the weakened ligand stabilization or the decreased charge repulsion between adjacent AIPNCs. The highly luminous $\mathrm{Ce}^{3}$ ${ }^{+}$-doped AIPNC colloids can be used as photonic ink. Fig. $1 \mathrm{~d}$ shows the emblem of the soft matter center of Guangdong University of Technology manufactured by screen printing of the $\mathrm{Ce}^{3+}$-doped AIPNC ink on a black substrate.

$\mathrm{Cs}^{+}+x \mathrm{Ce}^{3+}+\mathrm{Pb}^{2+}+3 \mathrm{Br}^{-} \rightarrow \mathrm{CsCe}_{x} \mathrm{PbBr}_{3}{ }^{3 x+}$.

TEM results in Fig. $2 \mathrm{a}-\mathrm{f}$ reveal that the as-prepared $\mathrm{Ce}^{3+}$-doped $\mathrm{CsPbBr}_{3}$ AIPNCs basically possess typical cubic morphologies, similar to the undoped $\mathrm{CsPbBr}_{3}$ AIPNCs synthesized without injecting $\mathrm{Ce}^{3+}$ into the microfluidic reactor. The sizes of the $\mathrm{CsPbBr}_{3}$ AIPNCs are
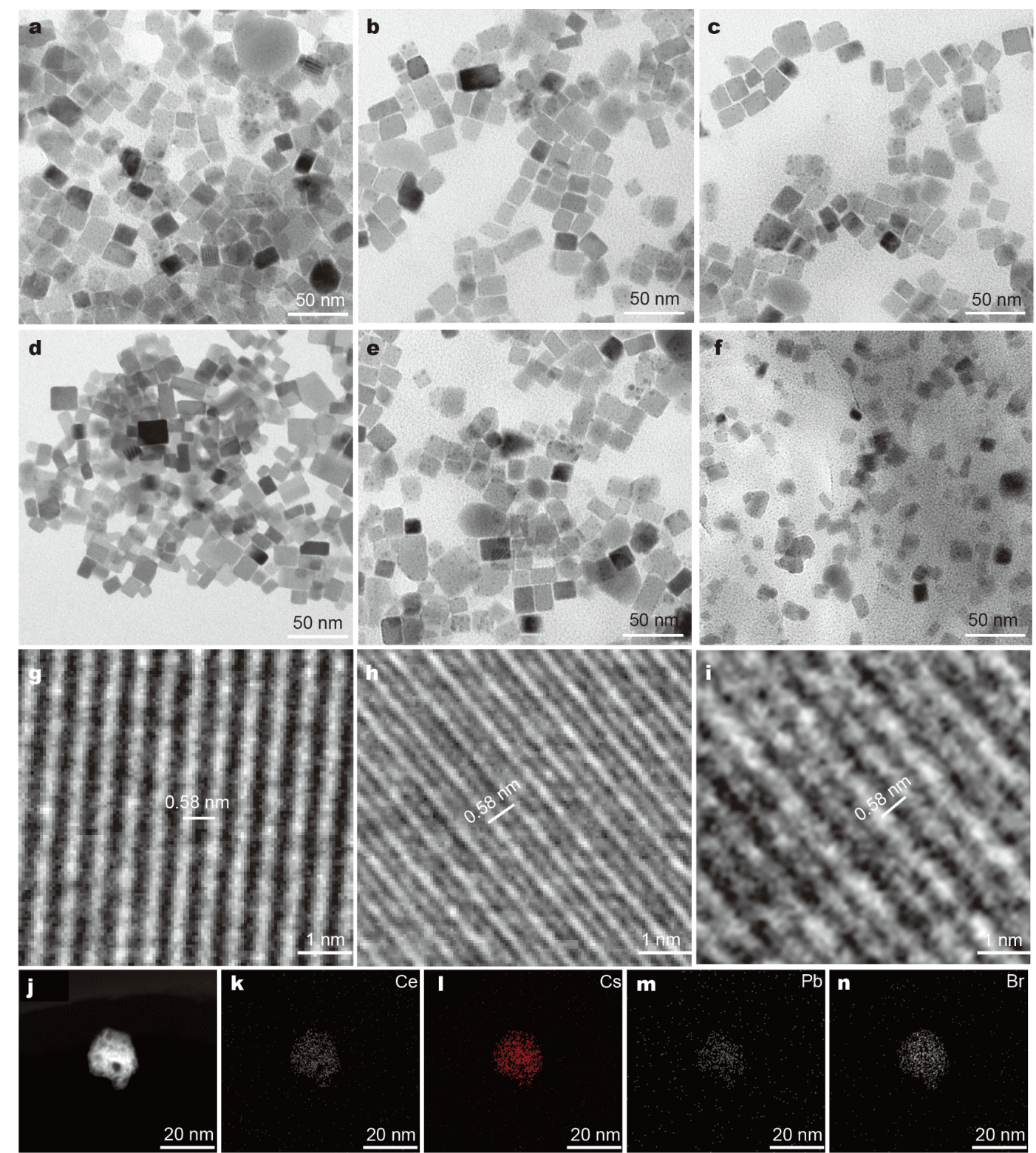

Figure 2 Crystal morphologies of the undoped and $\mathrm{Ce}^{3+}$-doped AIPNCs. (a-f) TEM images of the undoped and Ce ${ }^{3+}$-doped AIPNCs prepared by the microfluidic reactor. The $Q_{2} / Q_{1}$ ratios when producing the samples are $0 \%, 10 \%, 20 \%, 30 \%, 40 \%$ and $50 \%$, respectively. (g-i) The magnified highresolution TEM images of the representative samples, and the $Q_{2} / Q_{1}$ ratios when producing the samples are $0 \%, 30 \%$ and $50 \%$, respectively. (j-n) The HAADF-STEM image of single randomly selected $\mathrm{Ce}^{3+}$-doped AIPNC (the flow rate ratio is $30 \%$ ) and its corresponding EDS elemental mapping images of $\mathrm{Ce}, \mathrm{Cs}, \mathrm{Pb}$, and $\mathrm{Br}$. 
about $15 \mathrm{~nm}$ when the $Q_{2} / Q_{1}$ ratios are increased from $0 \%$ to $40 \%$, implying that the $\mathrm{Ce}^{3+}$ doping does not influence the basic crystal growth of the $\mathrm{CsPBrr}_{3}$ host and can avoid the change of optical properties caused by the size effect. However, the $\mathrm{Ce}^{3+}$-doped $\mathrm{CsPbBr}_{3}$ AIPNCs present sharply decreased size and irregular morphology when the flow rate ratio reaches $50 \%$. This can be attributed to the formation of excess nuclei at a high flow rate of the doping fluid. Therefore, the maximum $Q_{2} / Q_{1}$ ratio in this work is $50 \%$. The high-resolution TEM images in Fig. $2 \mathrm{~g}-$ $\mathrm{i}$ demonstrate that both the doped and the undoped $\mathrm{CsPbBr}{ }_{3}$ AIPNCs possess single crystal structures and clear lattice fringes with a spacing distance of about $0.58 \mathrm{~nm}$ corresponding to the lattice space of (101) plane. The EDS mapping images of the $\mathrm{Ce}^{3+}$-doped $\mathrm{CsPbBr}_{3}$ AIPNCs $\left(Q_{2} / Q_{1}=30 \%\right)$ as shown in Fig. $2 j-n$ demonstrate the existence of the $\mathrm{Ce}, \mathrm{Cs}, \mathrm{Pb}$ and $\mathrm{Br}$ in the hybrid nanocrystals. Fig. 3a illustrates that the powder XRD patterns of the as-synthesized doped and undoped $\mathrm{CsPbBr}_{3}$ AIPNCs are almost the same and possess cubic crystalline structures according to the Powder Diffraction File No. 54-0752 (Joint Committee on Powder Diffraction Standards, 2001). This result demonstrates that the $\mathrm{Ce}^{3+}$ doping does not change the crystalline forms of $\mathrm{CsPbBr}_{3}$ AIPNCs. However, as compared with the undoped
CsPbBr ${ }_{3}$ AIPNCs, a slight shift of the diffraction peak at (200) around $30^{\circ}$ toward larger angle is observed for the doped $\mathrm{CsPbBr}_{3}$ AIPNCs (Fig. 3b), indicating the decreased cell parameters and the decreased lattice plane gap as the result of the replacement of $\mathrm{Pb}^{2+}$ by $\mathrm{Ce}^{3+}$. The ICP-OES analysis reveals that the $\mathrm{Ce} / \mathrm{Pb}$ atomic ratios in the $\mathrm{Ce}^{3+}$-doped $\mathrm{CsPbBr}_{3}$ AIPNCs synthesized at different $Q_{2} / Q_{1}$ ratios are quantified to be $0 \%, 0.23 \%, 0.4 \%, 0.55 \%$, $1 \%$ and $0.5 \%$ as shown in Fig. 3c. It is convinced that controlling the ion doping concentration in AIPNCs by changing the flow parameters in the microfluidic reactor is an efficient and facile methodology. Furthermore, the optical properties of the doped and undoped $\mathrm{CsPbBr}_{3}$ AIPNCs were analyzed by steady-state UV-Vis absorption spectroscopy and PL emission spectroscopy. From the UV-Vis absorption spectra shown in Fig. 3d, it can be clearly seen that the incorporation of $\mathrm{Ce}^{3+}$ heteroions into $\mathrm{Cs} \mathrm{PbBr}_{3}$ AIPNCs induces a slight blue-shift of the characteristic absorption edge of $\mathrm{CsPbBr}_{3}$ AIPNCs due to the electronic structure modulation of the $\mathrm{Ce}^{3+}$-doped $\mathrm{CsPbBr}_{3}$ AIPNCs. Importantly, upon incorporation of $\mathrm{Ce}^{3+}$ into the $\mathrm{CsPbBr}_{3}$ AIPNCs, the PL emission wavelengths of the doped and undoped $\mathrm{CsPbBr}_{3}$ AIPNCs are located at around $520 \mathrm{~nm}$ (Fig. 3e). The maximum fluctuation of the emission wavelengths is only $2 \mathrm{~nm}$ as
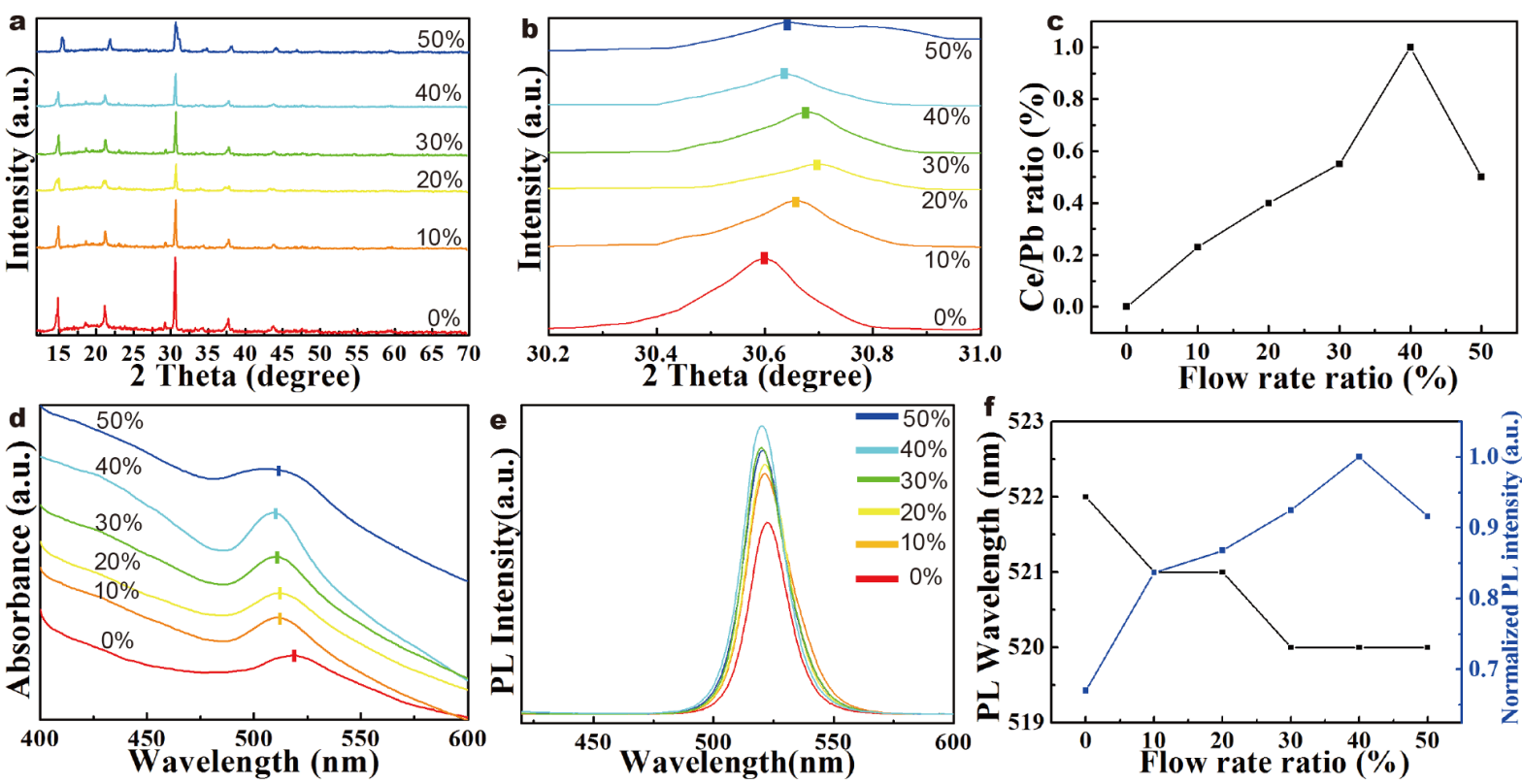

Figure 3 Crystal structures and optical properties of the undoped and $\mathrm{Ce}^{3+}$-doped AIPNCs. (a, b) Powder XRD patterns and the enlarged powder XRD patterns of the undoped and $\mathrm{Ce}^{3+}$-doped AIPNCs. (c) The $\mathrm{Ce}^{3+}$ doping concentrations in the $\mathrm{Ce}^{3+}$-doped AIPNCs fabricated at different flow rate ratios by the ICP-OES analysis. (d) UV-Vis absorption spectra of the undoped and $\mathrm{Ce}^{3+}$-doped AIPNCs. (e) The PL spectra of the undoped and $\mathrm{Ce}^{3+}$-doped AIPNCs (excitation at $365 \mathrm{~nm}$ ). (f) The central PL wavelengths and the corresponding normalized PL intensities of the undoped and Ce ${ }^{3+}$ doped AIPNCs. 
shown in Fig. 3f. However, the PL spectra show an obvious increase of the normalized PL intensity from 0.67 to 1 with the flow rate ratio increasing from $0 \%$ to $40 \%$ (Fig. 3e, f), indicating the enhancement effect of $\mathrm{Ce}^{3+}$ doping on the PL of $\mathrm{CsPbBr}_{3}$ AIPNCs. It should be noted that the PL intensity begins to decrease when the flow rate ratio reaches $50 \%$, possibly resulting from the decreased crystallinity of the $\mathrm{Ce}^{3+}$-doped $\mathrm{CsPbBr}_{3}$ AIPNCs. The photoluminescence quantum yield (PLQY) analysis also present that the quantum yields of the undoped and doped AIPNCs are 67.5\%, 71.5\%, 75.2\%, 81.8\%, 86.7\% and $79.5 \%$ with the flow rate ratio increasing from $0 \%$ to $50 \%$.

The structure stability is a significant concern of AIPNCs as the results of the dissociation of the ionic bonds, the hydrolysis of the metal ions and the oxidation of the halogen ions. It is manifest that the optical stability of the doped AIPNCs depends on their structure stabilities under certain conditions. The pretreatment of the AIPNC materials in the process of device manufacture is inevitably conducted under ambient conditions containing oxygen and moisture. Therefore, the PL evolution of the $1 \% \mathrm{Ce}^{3+}$-doped $\mathrm{CsPbBr}_{3}$ AIPNCs with the highest luminous efficiency is analyzed with the undoped
$\mathrm{CsPbBr}_{3}$ AIPNC as the control sample. The testing samples in the form of thin films were prepared by vacuum drying the AIPNC inks on a quartz plate. Results show that both the undoped and doped $\mathrm{CsPbBr}$ AIPNCs can emit bright green fluorescence under ambient conditions in the initial state as shown in Fig. 4a, b. The undoped $\mathrm{CsPbBr}_{3}$ nanocrystal shows a slight discoloration without isolation from oxygen and moisture with the aging time of $10 \mathrm{~d}$. Then, its green emission rapidly fades with the increase of aging time due to the dissociation effect of perovskite crystals to form mobile ions. The undoped $\mathrm{CsPbBr}_{3}$ nanocrystals almost lose the green fluorescence after 30-d aging, while the doped $\mathrm{CsPbr}_{3}$ nanocrystals show a slower attenuation process. When the aging time is increased to $20 \mathrm{~d}$, the PL intensity of the $\mathrm{Ce}^{3+}$-doped $\mathrm{CsPbBr}_{3}$ AIPNCs begins to decrease dramatically. When the aging time reaches $30 \mathrm{~d}$, the doped $\mathrm{CsPbBr}{ }_{3}$ AIPNCs can still emit the green fluorescence. The normalized PL intensities in Fig. 4c also demonstrate a better stability of the $\mathrm{Ce}^{3+}$-doped $\mathrm{CsPbBr}_{3}$ AIPNCs under ambient conditions than that of the undoped sample, probably due to the enhanced ionic bonds in the perovskite lattice by replacing the $\mathrm{Pb}^{2+}$ with $\mathrm{Ce}^{3+}$. When the $\mathrm{CsPbBr}_{3}$ AIPNCs are sealed in an LED chip, the lu-

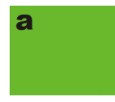

0

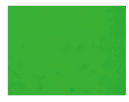

10

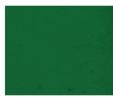

20

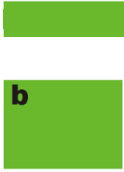

0

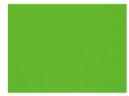

10
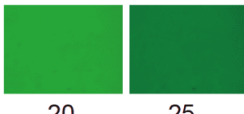

25

d

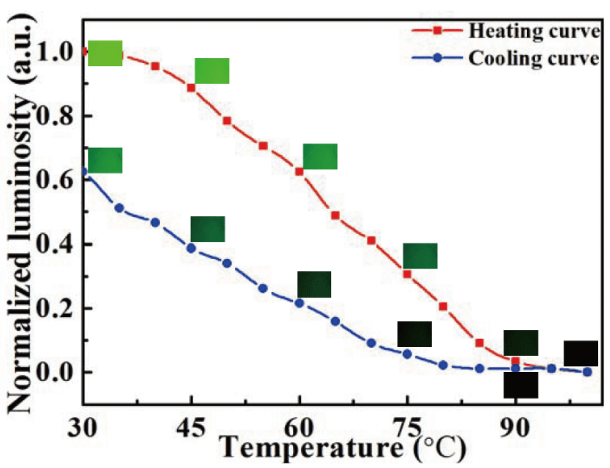

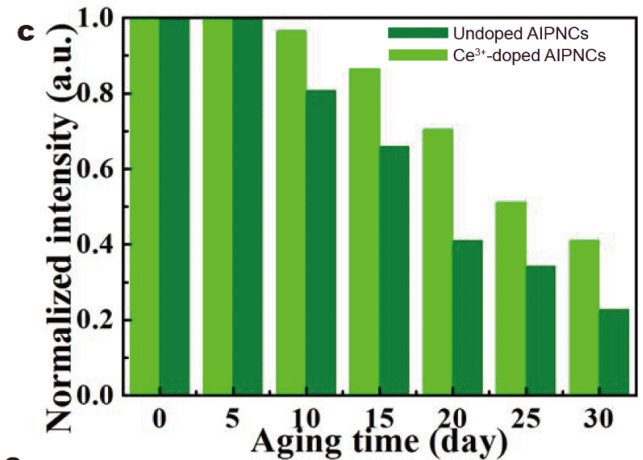

e

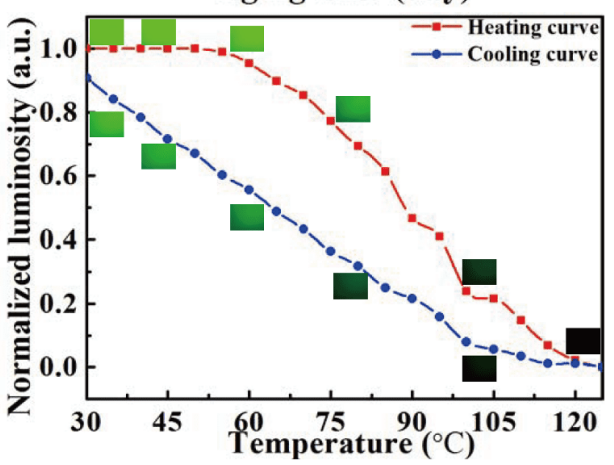

Figure 4 Optical stabilities of the undoped and $\mathrm{Ce}^{3+}$-doped AIPNCs. $(\mathrm{a}, \mathrm{b}) \mathrm{PL}$ images of the undoped and $1 \%$ Ce ${ }^{3+}$-doped AIPNCs after different aging times at ambient condition (excitation at $365 \mathrm{~nm}$ ). (c) The normalized PL intensities of the undoped and $1 \%$ Ce ${ }^{3+}$-doped AIPNCs after different aging times at ambient condition. $(\mathrm{d}, \mathrm{e})$ The normalized PL intensities of the undoped and $1 \% \mathrm{Ce}^{3+}$-doped AIPNCs at different temperatures in the heating-cooling cycle. The inserted images are the representative PL images (excitation at $365 \mathrm{~nm}$ ). 
minescence performance of the LEDs can be affected by the surrounding heat generated by the LED working circuit. Therefore, the PL stability of the doped and undoped $\mathrm{CsPbBr}_{3}$ AIPNCs against temperatures was also studied. The PL characteristics of the samples were recorded within a heat-cooling cycle. Results in Fig. 4d show that the green emission of the undoped $\mathrm{CsPbBr}_{3}$ AIPNCs presents a continuous weakening in the heating process. The downward trend is approximately linear. The undoped $\mathrm{Cs} \mathrm{PbBr}_{3}$ nanocrystals completely lose the green fluorescence when the temperature reaches $105^{\circ} \mathrm{C}$. When the temperature is gradually back to $30^{\circ} \mathrm{C}$, the green emission demonstrates a slow increase. However, the PL intensity of the undoped $\mathrm{CsPbBr}_{3}$ AIPNCs only recovers ca. $62 \%$ due to the temperature-dependent deformation of the perovskite octahedral units [36]. On the contrary, the $1 \% \mathrm{Ce}^{3+}$-doped $\mathrm{CsPbr}_{3}$ AIPNCs can reserve the green fluorescence when the temperature is below $60^{\circ} \mathrm{C}$. The green fluorescence finally disappears when the temperature reaches $125^{\circ} \mathrm{C}, 20^{\circ} \mathrm{C}$ higher than the undoped $\mathrm{Cs} \mathrm{PbBr}_{3}$ AIPNCs. When the temperature is gradually back to $30^{\circ} \mathrm{C}$, the green emission demonstrates a fast increase. The PL intensity of the $1 \% \mathrm{Ce}^{3+}$-doped $\mathrm{CsPbBr}_{3}$ AIPNCs can recover ca. $90 \%$ as shown in Fig. 4e. Overall, the stability improvement of the $\mathrm{Ce}^{3+}$-doped $\mathrm{CsPbBr}_{3}$ AIPNCs can be ascribed to the following mechanisms. One is that the incorporation of $\mathrm{Ce}^{3+}$ ions can enhance the formation energy, cause a slight lattice contraction, and hence stabilize the perovskite structures of the nanocrystals $[18,37]$. The other is that the Br-rich element can decrease the trap state and improve the stability of AIPNCs during the purification process and device fabrication $[37,38]$.

In order to analyze the optical properties of the AIPNC-based LED device, both the undoped and doped AIPNCs were sealed in UV-pumped LED chips as shown in Fig. 5a. The as-prepared AIPNCs were firstly mixed with silicone to from uniform AIPNC dispersions with the assistance of the ultrasound, and the concentrations of the undoped and doped AIPNCs in the dispersions were $1 \mathrm{wt} \%$. Then, the AIPNC dispersions were placed on the surface of a UV-LED chip of $370 \mathrm{~nm}$ and sealed by the epoxy resin under vacuum condition. The result in Fig. $5 \mathrm{a}$ shows that the AIPNC-based LED filled with $1 \%$ $\mathrm{Ce}^{3+}$-doped $\mathrm{CsPbBr}_{3}$ nanocrystals can emit bright green fluorescence when the working voltage is set to be $3.2 \mathrm{~V}$. The undoped and doped $\mathrm{CsPbBr}$ nanocrystals as the green phosphors were sealed in six UV LED chips respectively. The fluorescence emission spectra of the AIPNC-based green LED chips were recorded by an op- tical fiber fluorescent spectrometer. Results indicate that the central emission wavelengths of these LED chips are 537, 535, 536, 535, 535 and $534 \mathrm{~nm}$, as shown in Fig. 5b$\mathrm{g}$, and the slightly blue shift of the PL emission wavelength can be ascribed to the edge blue-shift of the optical absorption as described in Fig. 3d. In the meantime, the color purity of the LED chip reaches a highest level of $93.3 \%$ when the flow ratio is $40 \%$ due to the efficient doping of $\mathrm{Ce}^{3+}$ in the crystalline lattice of AIPNCs. When the flow rate ratio is further increased to $50 \%$, the color purity of the green LED chip is sharply decreased to $89.2 \%$ as the result of the decreased crystallinity of the doped AIPNCs.

The $0.1 \% \mathrm{Ce}^{3+}$-doped AIPNC as the green phosphor was coupled with commercial blue phosphor $\left(\mathrm{BaMgAl}_{10} \mathrm{O}_{17}: \mathrm{Eu}^{2+}\right)$ and red phosphor $\left(\mathrm{K}_{2} \mathrm{SiF}_{6}: \mathrm{Mn}^{4+}\right)$ to assemble a $3 \mathrm{D}$ layered white LED chip. Fig. $5 \mathrm{~h}$, i show that the central emission wavelengths of the commercial red phosphor $\left(\mathrm{K}_{2} \mathrm{SiF}_{6}: \mathrm{Mn}^{4+}\right)$ and blue phosphor $\left(\mathrm{BaMgAl}_{10} \mathrm{O}_{17}: \mathrm{Eu}^{2+}\right)$ are 628 and $460 \mathrm{~nm}$, respectively. The central emission wavelength of the green phosphor $\left(1 \% \mathrm{Ce}^{3+}\right.$-doped AIPNCs) is $535 \mathrm{~nm}$ as shown in Fig. 5 f. The green, red and blue phosphors (quantum yields of $86.7 \%, 72 \%$ and $85 \%$ ) show strong emission under UV light excitation (Fig. 5a, h, i). The blue, green and red phosphors were uniformly dispersed in silicone and then deposited on the UV LED chip from top to down. Fig. $5 j$ displays the schematic diagram of a 3D layered white LED with a combination of blue film outer layer, green film middle layer, and red film inner layer on top of a UVLED chip of $370 \mathrm{~nm}$. The PL spectrum of the white LED operated at $50 \mathrm{~mA}$ is shown in Fig. 5k. The 3D layered LED chip can emit bright white light as shown in the insert of Fig. 5k with correlated color temperature (CCT) of $10,436 \mathrm{~K}$, CIE color coordinates of $(0.261,0.317)$ and color-rendering index (CRI) of 72.1, and achieve a luminous efficiency of $10.47 \mathrm{~lm} \mathrm{~W}^{-1}$, which exhibits typical characteristics of cold white LEDs. The glowing characters "CHINA" in Fig. 51 show that the as-fabricated $\mathrm{Ce}^{3+}$-doped AIPNCs can be applied for the mass production of white LEDs, demonstrating the potential applications in lighting and display.

\section{CONCLUSIONS}

In conclusion, a microfluidic reactor is designed to produce the $\mathrm{Ce}^{3+}$-doped AIPNC based on the continuousflow reaction. The mechanism of the flow synthesis of the $\mathrm{Ce}^{3+}$-doped AIPNCs is the efficient physical mixing of the precursor ions in the confined micro-channel, the reaction nucleation of crystal seeds in the poor solvent and 

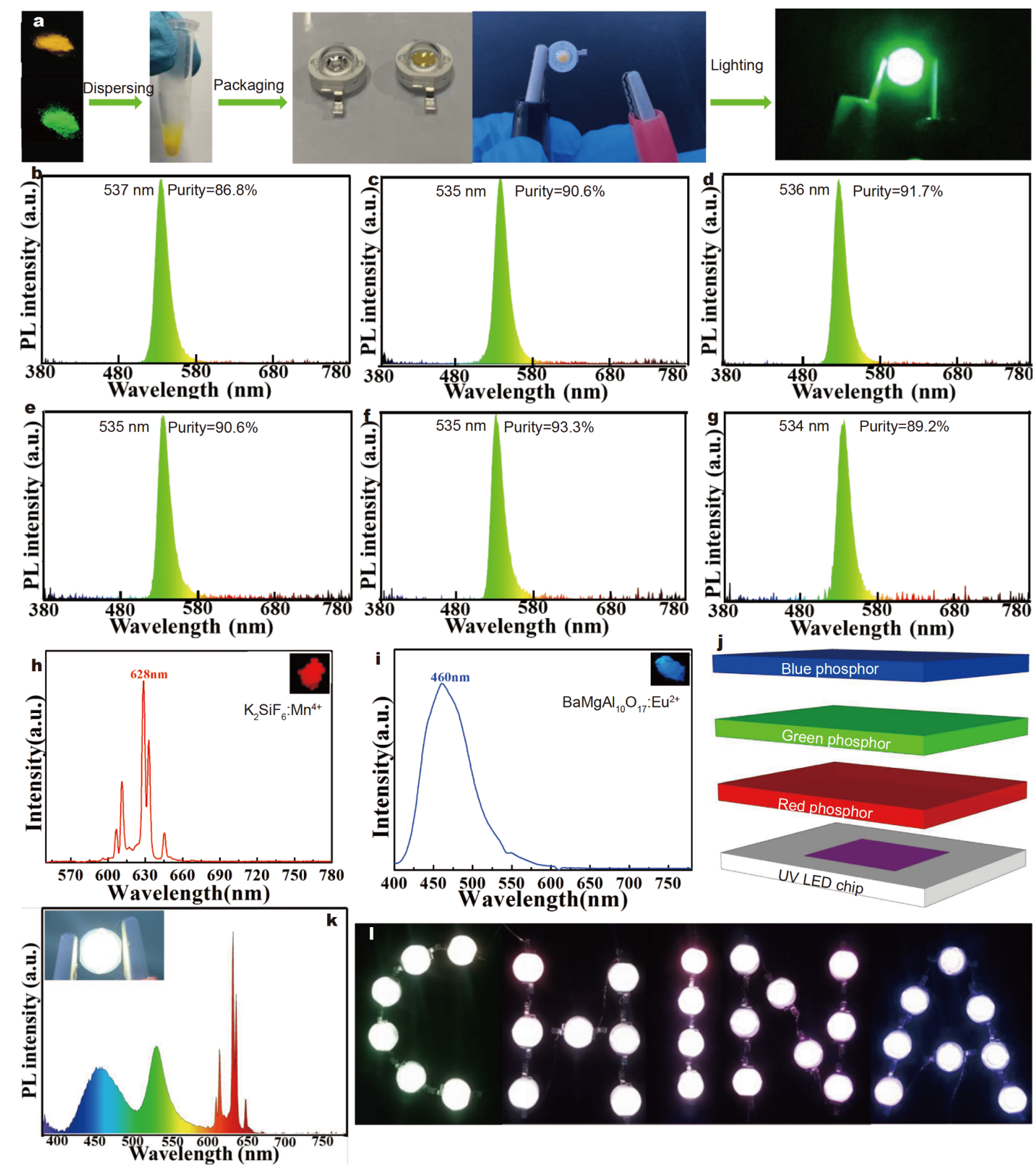

Figure 5 Fabrication and optical performance of the green and white LED devices based on the AIPNCs. (a) The fabrication procedure of the green LED devices, the right LED is filled with the $1 \% \mathrm{Ce}^{3+}$-doped $\mathrm{CsPbBr}_{3}$ AIPNCs. (b-g) The PL spectra of the green LED devices (excitation at $370 \mathrm{~nm}$ ), and the $Q_{2} / Q_{1}$ ratios when producing the AIPNCs are $0 \%, 10 \%, 20 \%, 30 \%, 40 \%$, and $50 \%$, respectively. (h) The PL spectrum of the red phosphor in the white LED devices (excitation at $370 \mathrm{~nm}$ ). (i) The PL spectrum of the blue phosphor in the white LED devices (excitation at $370 \mathrm{~nm}$ ). (j) The device structure of white LEDs, the blue, green and red phosphors from top to bottom are $\mathrm{BaMgAl}_{10} \mathrm{O}_{17}: \mathrm{Eu}^{2+}, 1 \% \mathrm{Ce}^{3+}-\mathrm{doped} \mathrm{CsPbBr}_{3}$ and $\mathrm{K}_{2} \mathrm{SiF}_{6}: \mathrm{Mn}^{4+}$, respectively. (k) The PL spectra of the white LED devices (excitation at $370 \mathrm{~nm}$ ). (l) The word CHINA lightened up by the white LED devices. 
the crystal growth of the doped AIPNCs along the flow direction. The doping concentration of $\mathrm{Ce}^{3+}$ can be facilely controlled by changing the flow parameters in the microfluidic reactor, and the highest value reaches $1 \%$. $\mathrm{The} \mathrm{Ce}^{3+}$ doping can significantly improve the PL efficiency of the AIPNCs. The quantum yield can be increased from $67.5 \%$ to $86.7 \%$. The PL stability of the AIPNCs at ambient condition and against high temperature also can be improved by $\mathrm{Ce}^{3+}$ doping. The $\mathrm{Ce}^{3+}-$ doped $\mathrm{CsPbBr}_{3}$ AIPNCs can be used to manufacture the green LEDs with a high color purity of $93.3 \%$ and the white LEDs with CCT of 10,436 K, CIE color coordinates of $(0.261,0.317)$ and CRI of 72.1. Together, the continuous and controllable synthesis of AIPNCs by microfluidic reactor provides new avenues for the application of high-performance optoelectronic materials and devices.

\section{Received 26 February 2020; accepted 26 April 2020; published online 10 June 2020}

1 Yang D, Li X, Zhou W, et al. $\mathrm{CsPbBr}_{3}$ quantum dots 2.0: Benzenesulfonic acid equivalent ligand awakens complete purification. Adv Mater, 2019, 31: 1900767

2 Yang W, Su R, Luo D, et al. Surface modification induced by perovskite quantum dots for triple-cation perovskite solar cells. Nano Energy, 2020, 67: 104189

3 Shi L, Meng L, Jiang F, et al. In situ inkjet printing strategy for fabricating perovskite quantum dot patterns. Adv Funct Mater, 2019, 29: 1903648

4 Yang D, Li X, Wu Y, et al. Surface halogen compensation for robust performance enhancements of $\mathrm{CsPb}_{3}$ perovskite quantum dots. Adv Opt Mater, 2019, 7: 1900276

$5 \mathrm{Li} \mathrm{J}, \mathrm{Xu} \mathrm{L}$, Wang T, et al. 50-fold EQE improvement up to $6.27 \%$ of solution-processed all-inorganic perovskite $\mathrm{CsPbBr}_{3}$ QLEDs via surface ligand density control. Adv Mater, 2017, 29: 1603885

6 Kim YH, Wolf C, Kim YT, et al. Highly efficient light-emitting diodes of colloidal metal-halide perovskite nanocrystals beyond quantum size. ACS Nano, 2017, 11: 6586-6593

7 Chen Q, Wu J, Ou X, et al. All-inorganic perovskite nanocrystal scintillators. Nature, 2018, 561: 88-93

8 Wang Y, Li X, Song J, et al. All-inorganic colloidal perovskite quantum dots: A new class of lasing materials with favorable characteristics. Adv Mater, 2015, 27: 7101-7108

9 Su R, Diederichs C, Wang J, et al. Room-temperature polariton lasing in all-inorganic perovskite nanoplatelets. Nano Lett, 2017, 17: $3982-3988$

10 Deng W, Zhang X, Huang L, et al. Aligned single-crystalline perovskite microwire arrays for high-performance flexible image sensors with long-term stability. Adv Mater, 2016, 28: 2201-2208

11 Huang S, Guo M, Tan J, et al. Novel fluorescence sensor based on all-inorganic perovskite quantum dots coated with molecularly imprinted polymers for highly selective and sensitive detection of omethoate. ACS Appl Mater Interfaces, 2018, 10: 39056-39063

12 Zeng J, Zhou H, Liu R, et al. Combination of solution-phase process and halide exchange for all-inorganic, highly stable
$\mathrm{CsPbBr}_{3}$ perovskite nanowire photodetector. Sci China Mater, 2019, 62: 65-73

13 Luo Q, Wang H, Yin X, et al. Hydrophilic perovskite microdisks with excellent stability and strong fluorescence for recyclable temperature sensing. Sci China Mater, 2019, 62: 1065-1070

$14 \mathrm{Xu}$ YF, Yang MZ, Chen BX, et al. A CsPbBr $\mathrm{Pr}_{3}$ perovskite quantum dot/graphene oxide composite for photocatalytic $\mathrm{CO}_{2}$ reduction. J Am Chem Soc, 2017, 139: 5660-5663

15 Chen K, Deng X, Dodekatos G, et al. Photocatalytic polymerization of 3,4-ethylenedioxythiophene over cesium lead iodide perovskite quantum dots. J Am Chem Soc, 2017, 139: 12267-12273

16 Gong Z, Zheng W, Gao Y, et al. Full-spectrum persistent luminescence tuning using all-inorganic perovskite quantum dots. Angew Chem Int Ed, 2019, 58: 6943-6947

17 Zhou Y, Chen J, Bakr OM, et al. Metal-doped lead halide perovskites: Synthesis, properties, and optoelectronic applications. Chem Mater, 2018, 30: 6589-6613

18 Yao JS, Ge J, Han BN, et al. $\mathrm{Ce}^{3+}$-doping to modulate photoluminescence kinetics for efficient $\mathrm{CsPbBr}_{3}$ nanocrystals based light-emitting diodes. J Am Chem Soc, 2018, 140: 3626-3634

19 Zhou Y, Yong ZJ, Zhang KC, et al. Ultrabroad photoluminescence and electroluminescence at new wavelengths from doped organometal halide perovskites. J Phys Chem Lett, 2016, 7: 2735-2741

20 Yong ZJ, Guo SQ, Ma JP, et al. Doping-enhanced short-range order of perovskite nanocrystals for near-unity violet luminescence quantum yield. J Am Chem Soc, 2018, 140: 9942-9951

21 Sun Q, Wang S, Zhao C, et al. Excitation-dependent emission color tuning from an individual Mn-doped perovskite microcrystal. J Am Chem Soc, 2019, 141: 20089-20096

22 Wang Y, Duan J, Yang X, et al. The unique dielectricity of inorganic perovskites toward high-performance triboelectric nanogenerators. Nano Energy, 2020, 69: 104418

23 Shapiro A, Heindl MW, Horani F, et al. Significance of Ni doping in $\mathrm{CsPbX}_{3}$ nanocrystals via postsynthesis cation-anion coexchange. J Phys Chem C, 2019, 123: 24979-24987

24 Miao X, Qiu T, Zhang S, et al. Air-stable $\mathrm{CsPb}_{1-x} \mathrm{Bi}_{x} \mathrm{Br}_{3}(0 \leq x \ll 1)$ perovskite crystals: Optoelectronic and photostriction properties. J Mater Chem C, 2017, 5: 4931-4939

25 Liu M, Zhong G, Yin Y, et al. Aluminum-doped cesium lead bromide perovskite nanocrystals with stable blue photoluminescence used for display backlight. Adv Sci, 2017, 4: 1700335

26 Jiang Q, Chen M, Li J, et al. Electrochemical doping of halide perovskites with ion intercalation. ACS Nano, 2017, 11: 1073-1079

27 Zhu FP, Yong ZJ, Liu BM, et al. Superbroad near-infrared photoluminescence from bismuth-doped $\mathrm{CsPbI}_{3}$ perovskite nanocrystals. Opt Express, 2017, 25: 33283-33289

28 Huang G, Wang C, Xu S, et al. Postsynthetic doping of $\mathrm{MnCl}_{2}$ molecules into preformed $\mathrm{CsPBrr}_{3}$ perovskite nanocrystals via a halide exchange-driven cation exchange. Adv Mater, 2017, 29: 1700095

29 Yu Y, Guo J, Sun L, et al. Microfluidic generation of microsprings with ionic liquid encapsulation for flexible electronics. Research, 2019, 2019: 6906275

30 Lin P, Wei Z, Yan Q, et al. Capillary-based microfluidic fabrication of liquid metal microspheres toward functional microelectrodes and photothermal medium. ACS Appl Mater Interfaces, 2019, 11: 25295-25305

31 Lin P, Wei Z, Yan Q, et al. Blue phase liquid crystal microcapsules: Confined 3D structure inducing fascinating properties. J Mater Chem C, 2019, 7: 4822-4827 
32 Nan L, Lai MYA, Tang MYH, et al. On-demand droplet collection for capturing single cells. Small, 2020, 16: 1902889

33 Mou CL, Wang W, Li ZL, et al. Trojan-horse-like stimuliresponsive microcapsules. Adv Sci, 2018, 5: 1700960

34 Lin P, Yan Q, Wei Z, et al. Chiral photonic crystalline microcapsules with strict monodispersity, ultrahigh thermal stability, and reversible response. ACS Appl Mater Interfaces, 2018, 10: 18289-18299

35 Chen L, Li Y, Fan J, et al. Photoresponsive monodisperse cholesteric liquid crystalline microshells for tunable omnidirectional lasing enabled by a visible light-driven chiral molecular switch. Adv Opt Mater, 2014, 2: 845-848

36 Li W, Vasenko AS, Tang J, et al. Anharmonicity extends carrier lifetimes in lead halide perovskites at elevated temperatures. J Phys Chem Lett, 2019, 10: 6219-6226

37 Zhang J, Zhang L, Cai P, et al. Enhancing stability of red perovskite nanocrystals through copper substitution for efficient lightemitting diodes. Nano Energy, 2019, 62: 434-441

38 Liu P, Chen W, Wang W, et al. Halide-rich synthesized cesium lead bromide perovskite nanocrystals for light-emitting diodes with improved performance. Chem Mater, 2017, 29: 5168-5173

Acknowledgements This work was supported by the National Natural Science Foundation of China (61805047), Guangdong Special Support Program (2017TX04N371), Guangzhou Science Technology and Innovation Commission (201807010108), the Natural Science Foundation of Guangdong Province (2019A1515011379), and Foshan Municipal Science and Technology Bureau Project (2015IT100162).

Author contributions Lin $\mathrm{P}$, Chen $\mathrm{Y}$ and Cheng $\mathrm{Z}$ designed the experiment. Chen H, Wei Z, Lin Y and Lin J performed the experiments. Lin $\mathrm{P}$, Chen $\mathrm{Y}$ and Cheng $\mathrm{Z}$ wrote the paper. All authors contributed to the general discussion.

Conflict of interest The authors declare that they have no conflict of interest.

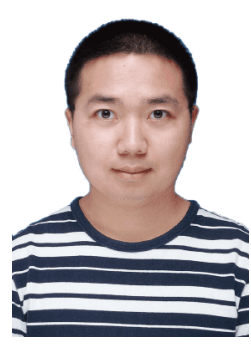

Pengcheng Lin is an associate professor in Guangdong Provincial Key Laboratory on Functional Soft Condensed Matter (Guangdong University of Technology). He received his $\mathrm{PhD}$ degree in polymer chemistry and physics from Northeastern University in 2016. He worked as a visiting scholar in the City University of Hong Kong from 2018 to 2019. His research interests include the manufacture of microfluidic chips, the microfluidic synthesis and application of optical materials.

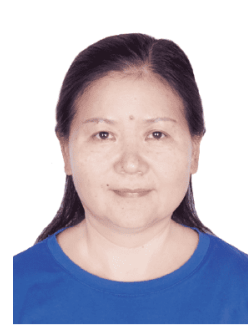

Ying Chen is a professor in Guangdong University of Technology, also the dean of the School of Materials and Energy and the executive director of Guangdong Provincial Key Laboratory on Functional Soft Condensed Matter. She received her $\mathrm{PhD}$ degree in chemical engineering from South China University of Technology in 2003. She joined Guangdong University of Technology as a lecturer in 1994, and was promoted to professor in 2008. Her research interests focus on the energy materials and energy system.

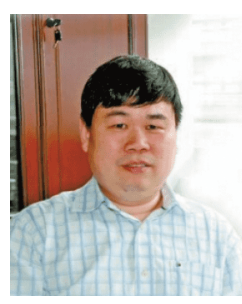

Zhengdong Cheng received his BSc degree in modern physics from the University of Science and Technology of China in 1990. He completed his $\mathrm{PhD}$ in physics under the supervision of Prof. Paul M. Chaikin at Princeton University in 1998. From 2002 to 2004, he was a post-doctoral fellow in Harvard University under the supervision of Prof. David A. Weitz. He joined Texas A\&M University as an assistant professor in 2004, and was promoted to professor in 2017. His current research interests focus on the design and application of microfluidic chips, optical materials and soft materials.

\section{微流控反应器中连续流动合成掺杂型全无机钻钛 矿纳米晶及其在发光二极管中的应用}

林鹏程 $^{1}$, 陈虹滨 ${ }^{1}$, 魏崭 ${ }^{1}$, 林映汝 ${ }^{1}$, 林景辉 ${ }^{1}$, 陈颖 ${ }^{1 *}$, 成正东 ${ }^{2 *}$

摘要 全无机钲钛矿纳米晶具有发射光谱窄、发光量子效率高和 发光波长可调等优点, 在光电子材料和器件领域具有广阔的应用 前景. 离子掺杂可以调节其原始的晶体结构和发光性能, 或者赋予 其额外的功能. 本文设计了一种基于连续流动反应制备 $\mathrm{Ce}^{3+}$ 掺杂的 全无机钻钛矿纳米晶的微流控反应器. 流动合成 $\mathrm{Ce}^{3+}$ 掺杂全无机钲 钛矿纳米晶的机理是前驱体离子在限域微通道中的有效物理混 合、晶种在不良溶剂中的反应成核以及全无机钻钛矿纳米晶沿着 流动方向的晶体生长. 利用光纤式吸收光谱仪和光纤式苂光光谱 仪可以对合成过程进行在线监测. 通过改变微流控反应器的流动 参数, 可以便捷地控制 $\mathrm{Ce}^{3+}$ 的掺杂浓度, 最高可达 $1 \% . \mathrm{Ce}^{3+}$ 掺杂可 以提高全无机钙钛矿纳米晶的光致发光效率和稳定性. $\mathrm{Ce}^{3+}$ 掺杂的 $\mathrm{CsPbr}_{3}$ 全无机钻钛矿纳米晶可用于制造色纯度高达 $93.3 \%$ 的绿色 发光二极管, 以及色温为 $10,436 \mathrm{~K} 、 \mathrm{CIE}$ 色坐标为 $(0.261,0.317)$ 、显 色指数 (CRI) 为 72.1 的白色发光二极管. 微流控反应器连续可控合 成全无机钙钛矿纳米晶为高性能光电材料和器件的应用开辟了新 途径. 